\title{
Factors Associated with Self Care Practices among Patients with Hepatitis
}

\section{Virus}

\author{
Heba Ramadan Ibrahim Ghazy, Nursing Educator \\ Technical Nursing Institute, Kafr El-Sheikh University \\ Nabila Ahmed Bedier, Professor \\ Medical Surgical Nursing, Faculty of Nursing, Alexandria University \\ Rasha Aly Yakout, Assistant Professor \\ Medical Surgical Nursing, Faculty of Nursing, Alexandria University
}

\begin{abstract}
Hepatitis $C$ virus $(H C V)$ is an important public health problem both in developed and developing countries. Living with hepatitis $C$ involves learning to live with the physical, emotional, social and financial consequences of the disease. All of these changes can affect patient's ability to cope with chronic HCV with profound negative impacts on self-care practices. Self-care as a part of daily living is the care taken by individuals towards their own health and well-being, which includes the care extended to their children, family, friends and others in neighborhoods and local communities. Self-care practices play an important role in disease management, treatment and achieving better health outcome. Objective: Identify factors associated with self-care practices among patients with hepatitis $C$ virus. Setting: The study was conducted at outpatient clinic of Liver Institute in Kafr El-Sheikh (Ministry of Health). Subjects: 340 adult patients diagnosed with HCV infection. Tools: Three tools were utilized for the purpose of data collection; socio-demographic and clinical data interview schedule, hepatitis $C$ virus patients' knowledge structured interview questionnaire, and hepatitis $C$ Virus self-care practices structured interview questionnaire. Results: There were multiple factors influencing patients' self-care practices including age, sex, educational level, marital status, type of work, income, residence and clinical onset and duration of disease, history of associated diseases and taking medications for these associated diseases. Conclusion: There were four factors together statistically significant influence patients self-care practices including educational level, age, income and residence. Recommendations: Development of health education programs for HCV patients and their families to teach them how to apply self-care practices and how to deal with factors affecting patients' self-care practices to avoid subsequent complications of HCV.
\end{abstract}

Keywords: Hepatitis C; Self-care practices.

\section{Introduction}

Hepatitis $\mathrm{C}$ virus (HCV) infection is a blood born infectious disease that damages the liver by inflammatory cells ${ }^{(1)}$. It is one of the main causes of chronic liver disease worldwide The long-term impact of $\mathrm{HCV}$ infection is highly variable, ranging from minimal histological changes to extensive fibrosis and cirrhosis with or without hepatocellular carcinoma $(\mathrm{HCC})^{(2)}$. The number of chronically infected persons worldwide is estimated to be about 160 million, and most of them are unaware of their infection ${ }^{(3)}$.
The World Health Organization (WHO, 2016) found that Egypt has the highest prevalence of $\mathrm{HCV}$ in the world, with approximately 22 percent of Egyptian blood donors testing positive for the disease. According to HCV Advocate, Egypt suffers from a particularly high morbidity and mortality rate, with 40,000 dying from HCV disease each year ${ }^{(4)}$.

Infection with $\mathrm{HCV}$ is a major public health problem in Egypt ${ }^{(5)}$. The disease is primarily transmitted parenteral, the most common mode of transmission. Mother to infant transmission; is also called vertical transmission is uncommon but it does 
occur $^{(6,7)}$. Sexual transmission of $\mathrm{HCV}$ through intercourse play role in ongoing spread of the disease ${ }^{(8)}$.

Many people with hepatitis $\mathrm{C}$ do not have symptoms and do not know that they are infected. If symptoms occur they can include: fatigue, weakness, muscle ache, and anorexia, but jaundice is rare. If symptoms occur with acute infection they can appear from 2 weeks to 6 months after infection. On the other hand, if symptoms occur with chronic hepatitis $\mathrm{C}$, they can take decades to develop ${ }^{(9)}$.

Hepatitis $\mathrm{C}$ virus treatment can delay or prevent many of the complications of disease $^{(10)}$. The current standard-of-care for hepatitis $\mathrm{C}$ involves taking one of two newly approved therapies, Sovaldi or Olysio, plus ribavirin and in many cases pegylated interferon as well ${ }^{(11)}$.

Reducing the burden of $\mathrm{HCV}$ infection and $\mathrm{HCV}$-related disease require implementation of primary prevention activities that reduce risks for contracting $\mathrm{HCV}$ infection and secondary prevention activities that reduce risks for liver and other chronic diseases in $\mathrm{HCV}$-infected persons $^{(12)}$. In addition, surveillance and activities evaluation are required to determine the effectiveness of prevention programs in reducing incidence of disease, identifying persons infected with $\mathrm{HCV}$, providing appropriate medical follow-up, and promoting healthy life styles and behaviors $^{(13)}$.

Patients coping with a chronic illness may find that the illness can impact life in a number of ways. One may become tired easily or be often in pain, experience changes in appearance or physical abilities, or finds that prescribed medications have undesirable side effects ${ }^{(14)}$. Patient who is unable to work after the onset of a chronic illness may worry about financial difficulties and experiences stress or anxiety as a result. Feelings of anger or depression may also affect those experiencing a chronic illness, as some people may find it difficult to perform self-care ${ }^{(15)}$.
Olivardia (2015), defined self-care as anything "that affirms and strengthens physical, psychological, relational, emotional, and spiritual well-being."(16). The three major factors associated with selfcare are symptoms associated with chronic hepatitis $\mathrm{C}(\mathrm{CHC})$, treatment the disease itself. Other factors can be classified into, demographic (Host factors), physical, psychosocial, comorbid conditions, patient's information and skills related to HCV. So ,in order to achieve better outcomes among patients with $\mathrm{HCV}$, it is essential to identify and understand factors associated with selfcare practices among patients with hepatitis C virus over time is important for the provision of appropriate and targeted interventions $^{(17)}$.

Moreover, they will enable nurse to play a significant role, in providing holistic care for these patients. This care will be individualized taking into consideration all aspects of patients' life physical, psychological and social, in order to enhance their health life ${ }^{(18)}$.

\section{Aim of the Study}

This study aimed to identify factors associated with self-care practices among patients with hepatitis $\mathrm{C}$ virus.

\section{Research Questions:}

What are the factors associated with self-care practices among patients with hepatitis $\mathrm{C}$ virus?

\section{Materials and Method}

\section{Materials}

Design: A descriptive research design was used to meet the aim of the study.

Setting: The study was conducted at outpatient clinic of Liver Institute in Kafr El-Sheikh (Ministry of Health).

Subjects: The Epi info program was used to estimate the sample size based on using 5\% acceptable error, $95 \%$ confidence coefficient, $50 \%$ expected frequency and population size of 2476 per year. The 
program revealed a minimum sample size to be 333 patients of hepatitis $\mathrm{C}$.

A convenient sample of 340 adult patients diagnosed with $\mathrm{HCV}$ infection. It was assigned from the above mentioned setting according to the following criteria:

- Adult patients aged from 21-60 years.

- Able to communicate verbally.

- Six months post diagnosis; since it is expected that this period is enough for patients to be adapted to the disease process ${ }^{(9)}$.

Tools: In order to achieve the aim of the study, three tools were utilized for data collection:

\section{Tool I: Socio-demographic and Clinical} Data Interview Schedule

This tool was developed by the researcher based on relevant related literature. It included two main parts:

Part I: Socio-demographic data included; patient's age, sex, level of education, marital status, occupation, income and residence.

Part II: Clinical data included; clinical history of patients and their families; family history related to hepatitis $\mathrm{C}$ virus, clinical onset of disease, duration of disease, type of medication used, adherence with medications and previous hospitalization.

\section{Tool II: Hepatitis C Virus Patients Knowledge $\quad$ Structured Interview Questionnaire (HPKSIQ)}

This tool was developed by the researcher based on relevant related literature $^{(19-21)}$, to assess patient's knowledge regarding hepatitis $\mathrm{C}$ virus. It included group of closed end questions related to the following eight areas of concern distributed as following:

1. Definition of hepatitis.

2. Risk factors of hepatitis C including; therapeutic maneuver, folk medication practices, occupational hazards and daily living practices.
3. Mode of transmission of hepatitis $\mathrm{C}$ included; statements related to ; blood or blood products transfusion, hemodialysis and dentists equipment and needle sticking in health care centers.

4. Signs \& symptoms of hepatitis C included; fatigue \&weakness, nausea \& vomiting, fever and jaundice.

5. Laboratory investigations needed for $\mathrm{HCV}$ diagnosis included; liver functions test, Polymerase chain reaction (PCR), HCV antibodies and liver biopsy.

6. Complications of hepatitis C included; chronic hepatitis, hyperbilrubinemia, cirrhosis, hepatocellular carcinoma.

7. Treatment of hepatitis $\mathrm{C}$ included; interferon, interferon and ribavirin, or both (combination therapy), sovaldi, sovaldi and ribavirin.

8. Side effects of the treatment included; nausea \&vomiting, anorexia, fatigue, exhaustion and myalgia.

Patients' knowledge was scored on 3 point Likert scale $(0=$ wrong answer or don't know, $1=$ correct and incomplete answer, $2=$ correct and complete answer). Total score was calculated then converted to percentage. Patients knowledge was calculated as follows: < 50\% was considered poor knowledge, $50 \%<65 \%$ fair knowledge, $65 \%<75 \%$ was considered good knowledge and $>75 \%$ very good knowledge.

Tool III: Hepatitis C Virus Self-Care \begin{tabular}{lll}
\hline Practices $\quad$ Structured & Interview \\
\hline Questionnaire (HSPSIQ) &
\end{tabular}

This tool was developed by the researcher based on relevant related literature $^{(22,23)}$ to assess patients self-care practices regarding hepatitis $\mathrm{C}$ virus. It included a group of closed end questions related to the following eight areas of concern distributed as following:

1. Exercise and daily physical activities: (7 statements) related to; perform daily activities, take breaks between acts, go to work regularly, activities 
order so don't take a great effort and time, work without help, do exercise regularly and going out for entertainment or leisure.

2. Rest and sleep: (7 statements) related to; sleeping for sufficient hours at the night, measures to overcome sleeping problems, improve of pattern and resting for adequate hours during the day.

3. Nutrition: (4 statements) related to; compliance with prescribed diet and following special diet to increase immunity and resisting virus.

4. Alcohol: (2 statements) related to; avoid alcohol substances and avoid drugs and tranquilizers.

5. Personal hygiene: (4 statements) related to; taking bath, oral hygiene and dental care, skin cleaning to reduce itching and use moisturizers for skin.

6. Adherence with medications: (6 statements) related to; take the prescribed medications, take appropriate dose, taking medications on time, the ability to get on medications and take medication without help.

7. Precautions that patients should practice to prevent transmission of disease: (8 statements) related to; sharing personal toileting items, notifying the doctor and nurse about HCV infection, commitment regarding sexual intercourse, avoid any folk medication practices, refusing blood or organ donation, cover any open wound with sterile dressing to prevent spread of infection.

8. Social interactions: (4 statements) related to; participate in family and friends activities, interest with other's problems, fun and sense of humor with family and visiting family and relatives.
Patient's self-care practices were scored on 3 point Likert scale ( $2=$ always, $1=$ sometimes and $0=$ never). Total score was calculated then converted to percentage. Patients' self-care practices were calculated as follows; $<50 \%$ was considered poor selfcare practices, $50 \%<75 \%$ moderate selfcare practices and $75 \%<100 \%$ was considered good self-care knowledge.

\section{Method}

1. Permission to carry out the study was obtained from the director of the chosen setting after explaining the purpose of the study.

2. The study tools were developed by the researcher after reviewing the relevant related literature, and it was translated into Arabic.

3. The tools were tested for content validity by five experts in the field of Medical- Surgical Nursing for completeness and clarity of items.

4. Reliability of tools was done using Cronbach Alpha Test. The tools of the study were applied on 30 patients. Reliability coefficient for tool II was 0.924 and for tool III was 0.915 .

5. A pilot study was carried out on 30 patients with viral hepatitis $\mathrm{C}$ to test the feasibility and the applicability of the tools and to identify the difficulties that may be faced during the application of the tools. Those patients were excluded from the sample.

6. Data collection was started, and continued for a period of 4 months from the beginning of May to the end of August 2016. Every patient was interviewed individually in the waiting room by the researcher using tools I, II and tool III to collect the necessary data related to patient's socio-demographic data, patients knowledge, and self-care practices. Each interview lasted about 30 minutes. 


\section{Ethical considerations:}

- Patient's consent for participation was obtained to carry out the study and each patient was informed about the purpose of the study.

- Patient's written consent was obtained after explanation of the study aim. Confidentiality and privacy were ascertained. Participant in the research was volunteered. The right to withdraw from the study was confirmed.

\section{Statistical Analysis}

Data were fed to the computer and analyzed using IBM SPSS software package version 20.0. (Armonk, NY: IBM Corp (25) Qualitative data were described using number and percent. Quantitative data were described using mean, standard deviation. Significance of the obtained results was judged at the $5 \%$ level.

\section{Results}

Table (1) shows the distribution of studied patients with hepatitis $\mathrm{C}$ virus according to socio-demographic characteristics. In relation to age, it can be noticed that $43.8 \%$ of the studied patients were in the age group $41<51$ years, most of the studied patients were married $(80.3 \%)$, the highest percentage of them had insufficient income to fulfill daily requirements $(63.5 \%)$.

Table (2) shows the distribution of studied patients with hepatitis $\mathrm{C}$ virus according to their clinical data. More than half of the studied patients had a family member infected with HCV (59.1\%). Eighty three percent of them were taking medications for associated diseases, while more than half were taking medications regularly (59.0\%). The results denoted that the majority of studied patients had previous hospitalization $(86.5 \%)$.

Table (3) denotes the distribution of studied patients according to score and mean percent score of their total knowledge level. More than half of studied patient's had poor knowledge level (52.6\%), with a mean \pm SD (12.5 \pm 5.4$)$.

Table (4) illustrates the distribution of studied patients according to total mean percent score of self-care practices items related to $\mathrm{HCV}$. This table shows that more than half of the studied patients $(51.5 \%)$ had moderate total self- care practices level related to $\mathrm{HCV}$.

Table (5) conveys Multivariate analysis logistic regression for factors affecting self care practices. This table revealed that, there were four factors together statistically significant influence patients self care practices including educational level, age, income and residence $(\mathrm{P} \leq 0.05)$.

\section{Discussion}

Hepatitis C viral infection is one of the most contagious diseases that have great social and economic impact which may touch the future of the young generation and hinder the community ${ }^{(2)}$.

Hepatitis $\mathrm{C}$ virus (HCV) infection is associated with multiple factors affecting self care practices. Therefore, the aim of the study was to identify factors influencing self care practices among patients with chronic $\mathrm{HCV}^{(18)}$.

Discussion of the findings in the present study covers three main parts. The first part, deals with socio-demographic characteristics and clinical data. The second part deals with patient's knowledge about $\mathrm{HCV}$ infection and self care practices related to $\mathrm{HCV}$, and the third part deals with relation between patient's knowledge and self care practices related sociodemographic characteristics \& clinical data of $\mathrm{HCV}$ patients as well as between $\mathrm{HCV}$ patient's knowledge and their self care practices.

The present study revealed that more than one third of patients were in the age group of 41-50 years. This finding agrees with Branndt $(2010)^{(27)}$ and Danilova et al. $(2011)^{(28)}$. They illustrated that the prevalence rate of $\mathrm{HCV}$ is higher in old persons than in younger one. 
As regards to sex, the findings of present study showed that more than half of the participated patients were males. This result was in the same line with Ibrahim and Madian $(2011)^{(29)}$. They illustrated that most of the studied patients were males On the other hand, this result contradicts Youssef et al. $(2017)^{(30)}$, they found that females were more exposed than males to hepatitis $\mathrm{C}$.

In relation to educational level, the present study findings revealed that illiterate patients formed the greatest proportion of the sample. This finding is supported by Mohamed et al. (2013) $)^{(31)}$, who found an association between illiteracy and many false traditional practices and unhealthy behaviors associated with increased risk of $\mathrm{HCV}$ infection.

Concerning occupation, it was observed that housewives represented the highest percentage of the sample. This result was in harmony with Abo-Elmataty $(2014)^{(32)}$ who found that, the majority of the female participated patients were housewives. On the other hand this finding was contradicted with Porter (2011) ${ }^{(33)}$, and Alavi and Hajiani (2011) ${ }^{(34)}$. They stated that most of the studied patients had professional hazards.

Related to the marital status, the results of the present study clarified that, approximately more than half of participants' patients were married. This finding may be related to many variables such as being unaware of methods of infection with $\mathrm{HCV}$ or sex that involves blood as during menstruation ${ }^{(35)}$. This finding was in agreement with Benova et al. $(2015)^{(36)}$, they found that marriage is a risk factor for HCV sero-positively.

Regarding family income, the present study finding revealed that the majority of patients family income who insufficient. This finding was matched with Jayasekera et al. (2014) ${ }^{(37)}$ who illustrated that the majority of $\mathrm{HCV}$ positive patients had low income or low socioeconomic status. However, Suthar and Harries et al. $(2015)^{(38)}$ mentioned that people in low and middle income countries remain without access to information about disease prevention, diagnostic producers, care and treatment.

As for residence, the results found that the highest percentage of participated patients were from rural areas. This result of the present study was in line with Amer et al. $(2015)^{(39)}$ who reported that most of their sample was from rural areas.

In relation to family and medical history, the findings of the present study showed that more than half of participation patients had family history of HCV. This finding was also supported by El-Berdan $(2014)^{(40)}$, he found that more than half of $\mathrm{HCV}$ patients had positive family history of hepatitis $\mathrm{C}$.

Concerning patient's past medical history; the majority of the studied patients discovered their disease accidentally. This finding was explained by Branndt (2010) ${ }^{(27)}$ and Ibrahim \& Madian (2011) ${ }^{(29)}$. In their study they found that most of patients with acute and chronic hepatitis $\mathrm{C}$ infection were asymptomatic. In contrast to this finding; McHutchision et al. $(2010)^{(41)}$, found that more than one-fourth of studied $\mathrm{HCV}$ patients discovered their disease when they complained from some symptoms.

Regarding patient's knowledge about $\mathrm{HCV}$, the current study revealed that, the most of the studied patients had incomplete knowledge about definition, risk factors, mode of transmission, laboratory investigations and treatment of HCV. These findings were supported by Jean et al. $(2010)^{(42)}$, and Proeschold-Bell et al. $(2011)^{(43)}$ they found that, the majority of patients did not know risk factors, mode of transmission and treatment of $\mathrm{HCV}$.

Concerning exercise and daily physical activities, the study findings revealed that, most of studied patients sometimes had selfcare practices. This may be related to fatigue, weakness, and neuropsychiatric (depression) side effects associated with interferon therapy. These findings are supported by Seaward (2009) ${ }^{(44)}$ who stated 
that the majority of patients feel tired ,did not accomplish heavy activity. In contrast to these findings, Stoller et al. (2009) ${ }^{(45)}$ reported that the majority of patients after diagnosis of $\mathrm{HCV}$ exercised daily (walking, swimming, yoga) due to their benefits on liver function, and improving immunity.

In relation to rest and sleep, the results of the present study illustrated that, most of studied patients sometimes had decrease sleeping during night and they expressed their inability to sleep well. This finding was in agreement with Highleyman $(2010)^{(46)}$, and Kallman et al. (2010) ${ }^{(47)}$ who mentioned that up to sixty percent of patients with chronic hepatitis $\mathrm{C}$ experience sleep problems.

In relation to nutrition, the study revealed that most of studied patients sometimes adherence with prescribed diet, following special diet to increase immunity and resist virus. This result may be related to specific Egyptian traditions. Moreover, it may be due to lack of knowledge about hazards of this food negative effect on patients' response to $\mathrm{HCV}$ therapy and accelerated complications of $\mathrm{HCV}$. This finding agreed with Sabry $(2009)^{(48)}$, who found that, the majority of studied patients had unbalanced diet as well as unhealthy dietary habits. On the other hand, this finding was contradicted with Stoller et al. $(2009)^{(45)}$ who found that the majority of patients avoided unhealthy food but not eat allowed food

Additionally, the study revealed that, most of the studied patients, always avoid drinking alcohol and any drugs and tranquilizers without doctors order. This result is confirmed by the study carried by Sallam (2009) ${ }^{(49)}$, who found that the majority of $\mathrm{HCV}$ patients did not drink alcohol.

Concerning personal hygiene, the findings of the present study revealed that most of studied patients always had self care practices about taking bath sometimes performing self-care practices related to skin cleaning to reduce itching, oral hygiene and dental care and using moisturizers for skin. This finding was contraindicated with Zuberi $(2010)^{(50)}$ who found that the most of HCV patients had a number of bathing, tooth brushing, and their general looking and grooming clothes became worn due to lack of interest, side effects of medication and lack of time.

Regarding adherence with medications, the present results showed that the majority of HCV patients reported that, they always had self-care about taking the prescribed medications, avoided medication in the event of side effects, took the appropriate dose, in appropriate time, had ability to get medications and take medication without help. This finding was explained by Rashed et al. (2009) ${ }^{(51)}$ who found that, most of HCV patients adherence with treatment as they hoped to get completely cured.

As regards precautions that the patients should be practicing to prevent the transmission of disease, the present results noted that, most of the studied patients always had self-care practices about not allowing others to use personal toileting items, commitment regarding sexual intercourse. This finding was contraindicated with Stoller et al. (2009) ${ }^{(45)}$, they concluded that, the lowest percentage of patients followed health behaviors to prevent transmission of $\mathrm{HCV}$ to others.

As for total self-care practices in the present study, the highest percentage of studied patients had poor self-care practices related to exercise \& daily physical activities and moderate self-care practices related to rest \& sleep, nutrition, social interactions and total self-care practices. The only good self care practices were related to avoiding alcohol intake, precaution that the patients should practice to prevent the transmission of disease and adherence with medications. This may be due to lack of patients knowledge which helps them in performing good self- care practices.

In relation to social interactions; the study revealed that most of the studied patients sometimes had self-care practices 
about, participating with family and friends in activities, interested with others problem. This finding was in agreement with Khuwaja et al. (2002) ${ }^{(52)}$ who stated that, chronic HCV may cause a sense of stigmatization in the patients leading to feeling of shame and rejection.

As regards the relation between total patient's knowledge level about HCV and socio-demographic characteristics of studied patients, a statistically significant relation was found between patient's total knowledge level and patients age and patient educational level where the highest percentage of poor total knowledge level were found among older patients and illiterate patients. This finding is supported by Younossi et al. $(2010)^{(53)}$ who stated that there was a significant relation between patient's knowledge and their level of education and age.

In this study, there were statistically significant relations between total patient's knowledge levels and patients work and income. Poor level of knowledge was found among manual works and patients who had insufficient income. This finding is supported by Tamayo et al. $(2016)^{(54)}$ who mentioned that people in low and middle income countries remain without access to information about disease prevention, diagnostics procedures, care and treatment of $\mathrm{HCV}$.

Moreover, the results showed no statistically significant difference between total patient's knowledge levels and patients' sex, marital status and residence. This finding is congruent with the findings of Khuwaja et al. (2002) $)^{(52)}$ who found that there were no significant differences between the patient's knowledge related to $\mathrm{HCV}$ and their sex, area of residence, and physical condition.

As regards the relation between total self-care practices and socio-demographic characteristics of the studied patients, the present study revealed a statistically significant relation between total patient's self-care practices and patients age and level of education where moderate self-care practices about $\mathrm{HCV}$ was observed among older and low educated patients. This finding is contraindicated with Sallam $(2009)^{(49)}$ who pointed no statistically significant relation between age \& level of education and self-care practices among HCV patients.

Moreover, the results showed statistically significant relations between total patient's self- care practices and patient's sex and residence. This study showed that females patients in rural areas had moderate self-care practices, while males had good self-care practices. This result disagreed with Garieb (2009) ${ }^{(55)}$, he found that there was no significant difference between males and females who live in rural or urban in relation to their total self- care practices

Additionally, the results revealed that there was a statistically significant relation between total patient's self-care practices and patient's work and marital status. Moderate self -care practices about $\mathrm{HCV}$ was found among housewives married patients. This result disagreed with Sallam $(2009)^{(49)}$ who found that the marital status didn't have effect on patients self- care practices among $\mathrm{HCV}$ patients. This finding may be due to low monthly income that didn't give them the opportunity to seek medical care which affected their self-care practices.

Also, there was statistically significant relation between total patient's self care practices and patient's income. Moderate self -care practices about HCV was found among patients with insufficient income. This result come in line with Sallam $(2009)^{(49)}$ who found that insufficient income among patients didn't give them the opportunity to seek medical care and cover the needs of their family which affected their self-care practices.

As regards the relation between total patient's self-care practices and clinical data, the present results verified statistically significant relations between total patient's self-care practices and onset and duration of disease where moderate self-care practices 
about $\mathrm{HCV}$ was found among patients who had symptoms and suffered from the disease since 4 years. These findings may be due to patients with chronic hepatitis $\mathrm{C}$ have symptoms which have a huge impact on patient's self care ${ }^{(18)}$.

Another statistically significant relation was found between total patient's self -care practices and patients who had chronic associated disease and were taking medications related to the chronic associated disease. Moderate self-care practices about $\mathrm{HCV}$ was found among patients who had chronic diseases and took medications. This may be due to the negative impact of chronic disease ${ }^{(18)}$.

As regards the relation between total self-care practices of the studied patients and total knowledge level, The results showed that, the highest percentages of poor knowledge were associated with moderate self-care while, the highest percentage of very good knowledge levels were associated with good self-care practices.

Finally the present study findings verified that there were four factors together statistically significant influence patients self care practices including educational level, age, income and residence which requires more focusing and caring effort to provide optimal self- care practices ${ }^{(17)}$, this help HCV patients to comply with self -care practices in order to improve their quality of life and reduce the present and expected burden of hepatitis $\mathrm{C}$ virus.

\section{Conclusion}

Based on the findings of the present study, it can be concluded that, more than half of the studied patients with HCV had poor total knowledge and moderate total self-care practices. In addition, the majority of the studied patients had poor self-care practices related to exercise and daily physical activities and more than one-third of them had moderate self-care practices related social interactions and rest \& sleep. Moreover, there were four factors together statistically significant influence patients self care practices including educational level, age, income and residence.

\section{Recommendations}

Based upon the findings of the current study, and in order to promote self care practices among patients with hepatitis $\mathrm{C}$ virus the following items are recommended:

1. Development of health education programs for HCV patients and their families to teach them how to apply self -care practices and how to deal with factors affecting patients self care practices to avoid subsequent complications of $\mathrm{HCV}$.

2. Inform $\mathrm{HCV}$ patients and their families about how to avoid $\mathrm{HCV}$ transmission of infection to others.

3. Develop manual guideline to nurses working with HCV patients about recent HCV self -care practices.

4. Raise the community awareness regarding $\mathrm{HCV}$ specific risk factors and behaviors, mode of transmission and preventive measures through mass media. 
Table (1): Distribution of the studied patients with hepatitis $\mathbf{C}$ virus in relation to their sociodemographic characteristics $(\mathbf{N}=\mathbf{3 4 0})$

\begin{tabular}{|c|c|c|}
\hline Socio-demographic data & No & $\%$ \\
\hline \multicolumn{3}{|l|}{ Age (years) } \\
\hline $21<31$ & 60 & $17.6 \%$ \\
\hline $31<41$ & 53 & $15.6 \%$ \\
\hline $41<51$ & 149 & $43.8 \%$ \\
\hline $51-60$ & 78 & $22.9 \%$ \\
\hline \multicolumn{3}{|l|}{ Sex } \\
\hline Male & 180 & $52.9 \%$ \\
\hline Female & 160 & $47.1 \%$ \\
\hline \multicolumn{3}{|l|}{ Educational level } \\
\hline Illiterate & 139 & $40.9 \%$ \\
\hline Read \& write & 23 & $6.8 \%$ \\
\hline Primary & 19 & $5.6 \%$ \\
\hline Preparatory & 15 & $4.4 \%$ \\
\hline Diploma & 79 & $23.2 \%$ \\
\hline Secondary & 25 & $7.4 \%$ \\
\hline University & 40 & $11.8 \%$ \\
\hline \multicolumn{3}{|l|}{ Work } \\
\hline Manual & 104 & $30.6 \%$ \\
\hline Professional & 86 & $25.3 \%$ \\
\hline Housewife & 150 & $44.1 \%$ \\
\hline \multicolumn{3}{|l|}{ Marital status } \\
\hline Single & 20 & $5.9 \%$ \\
\hline Married & 273 & $80.3 \%$ \\
\hline Divorced & 12 & $3.5 \%$ \\
\hline Widow & 35 & $10.3 \%$ \\
\hline \multicolumn{3}{|c|}{ Income from patients point of view } \\
\hline Insufficient & 216 & $63.5 \%$ \\
\hline Sufficient & 116 & $34.1 \%$ \\
\hline More than sufficient & 8 & $2.4 \%$ \\
\hline \multicolumn{3}{|l|}{ Residence } \\
\hline Rural & 213 & $62.6 \%$ \\
\hline Urban & 127 & $37.4 \%$ \\
\hline
\end{tabular}


Table (2): Distribution of studied patients with hepatitis $C$ virus according to their clinical data $(\mathrm{N}=340)$

\begin{tabular}{|c|c|c|}
\hline Clinical data & No & $\%$ \\
\hline $\begin{array}{l}\text { Family history related to } \mathrm{HCV} \\
\text { Yes } \\
\text { No }\end{array}$ & $\begin{array}{l}201 \\
139\end{array}$ & $\begin{array}{l}59.1 \% \\
40.9 \%\end{array}$ \\
\hline $\begin{array}{l}\text { Patient clinical data: } \\
\text { Clinical onset of disease } \\
\text { Appearance of signs\& symptoms } \\
\text { Accidentally } \\
\text { When doing laboratory investigations for HCV. }\end{array}$ & $\begin{array}{c}36 \\
271 \\
33\end{array}$ & $\begin{array}{l}10.6 \% \\
79.7 \% \\
9.7 \%\end{array}$ \\
\hline $\begin{array}{l}\text { Duration of disease (years) } \\
<1 \text { year } \\
1<2 \\
2<3 \\
3<4 \\
4<5 \\
5+\end{array}$ & $\begin{array}{l}61 \\
66 \\
84 \\
68 \\
45 \\
16\end{array}$ & $\begin{array}{l}17.9 \% \\
19.4 \% \\
24.7 \% \\
20.0 \% \\
13.2 \% \\
4.7 \%\end{array}$ \\
\hline $\begin{array}{l}\text { History of associated diseases } \\
\text { Yes } \\
\text { No }\end{array}$ & $\begin{array}{c}94 \\
246\end{array}$ & $\begin{array}{l}27.6 \% \\
72.4 \%\end{array}$ \\
\hline $\begin{array}{l}\text { If yes, what are these diseases }(\mathbf{n}=\mathbf{9 4}) \\
\text { Cardiac diseases } \\
\text { Renal diseases } \\
\text { Diabetes mellitus } \\
\text { Respiratory diseases } \\
\text { Hypertension } \\
\text { Arthritis }\end{array}$ & $\begin{array}{c}1 \\
6 \\
36 \\
6 \\
38 \\
47\end{array}$ & $\begin{array}{c}1.1 \% \\
6.4 \% \\
38.3 \% \\
6.4 \% \\
40.4 \% \\
50.0 \%\end{array}$ \\
\hline $\begin{array}{l}\text { Take medications for these associated diseases }(n=94) \\
\text { Yes } \\
\text { No }\end{array}$ & $\begin{array}{l}78 \\
16\end{array}$ & $\begin{array}{l}83 \% \\
17 \%\end{array}$ \\
\hline $\begin{array}{l}\text { Take medications regularly }(\mathbf{n}=\mathbf{7 8}) \\
\text { Yes }\end{array}$ & 46 & $59.0 \%$ \\
\hline $\begin{array}{l}\text { No } \\
\text { Previous hospitalization }\end{array}$ & 32 & $41.0 \%$ \\
\hline $\begin{array}{l}\text { Yes } \\
\text { No } \\
\text { What is the reason }(n=294)\end{array}$ & $\begin{array}{c}294 \\
46\end{array}$ & $\begin{array}{l}86.5 \% \\
13.5 \%\end{array}$ \\
\hline $\begin{array}{l}\text { Blood transfusion } \\
\text { Operation } \\
\text { Treat schistosomiasis } \\
\text { Visit the dentist }\end{array}$ & $\begin{array}{c}41 \\
220 \\
89 \\
240\end{array}$ & $\begin{array}{l}13.9 \% \\
74.8 \% \\
30.3 \% \\
81.6 \%\end{array}$ \\
\hline
\end{tabular}


Table (3): Distribution of studied patients according to score and mean percent score of their total knowledge level $(\mathrm{N}=340)$

\begin{tabular}{|l|c|c||}
\hline Total knowledge level & No & \% \\
\hline Poor & 179 & $52.6 \%$ \\
Fair & 45 & $13.2 \%$ \\
Good & 25 & $7.4 \%$ \\
Very good & 91 & $26.8 \%$ \\
\hline Min. score - Max. score & \multicolumn{2}{|c|}{$0-26$} \\
\hline Range & \multicolumn{2}{|c|}{$5-23$} \\
Mean \pm SD & \multicolumn{2}{|c|}{$12.5 \pm 5.4$} \\
\hline
\end{tabular}

*: Statistically significant at $P<0.05$

- Poor $<50 \%$

- Fair $50 \%<65 \%$

- Good $65 \%<75 \%$

- Very good $>75 \%$

Table (4): Distribution of studied patients according to total mean percent score of self- care practices items related to $\mathrm{HCV}(\mathrm{N}=340)$

\begin{tabular}{|l|c|c|c|c|c|c|c||}
\hline \multirow{2}{*}{ Self care practice items } & \multicolumn{2}{|c|}{ Poor } & \multicolumn{2}{c|}{ Moderate } & \multicolumn{2}{c|}{ Good } & \multirow{2}{*}{ Mean \pm SD } \\
\cline { 2 - 7 } & No & $\%$ & No & $\%$ & No & $\%$ & \\
\hline $\begin{array}{l}\text { Exercise and daily } \\
\text { physical activity }\end{array}$ & 159 & $46.8 \%$ & 80 & $23.5 \%$ & 101 & $29.7 \%$ & $7.7 \pm 3.8$ \\
\hline Rest and sleep & 151 & $44.5 \%$ & 163 & $47.9 \%$ & 26 & $7.6 \%$ & $3.5 \pm 1.3$ \\
\hline Nutrition & 0 & $0.0 \%$ & 204 & $60.0 \%$ & 136 & $40.0 \%$ & $5.6 \pm 1.9$ \\
\hline Alcohol intake & 0 & $0.0 \%$ & 0 & $0.0 \%$ & 340 & $100.0 \%$ & $4.0 \pm 0.0$ \\
\hline Personal hygiene & 35 & $10.3 \%$ & 137 & $40.3 \%$ & 168 & $49.4 \%$ & $6.0 \pm 1.9$ \\
\hline Social interactions & 24 & $7.1 \%$ & 163 & $47.9 \%$ & 153 & $45.0 \%$ & $7.4 \pm 2.5$ \\
\hline $\begin{array}{l}\text { Adherence with } \\
\text { medications }\end{array}$ & 27 & $7.9 \%$ & 107 & $31.5 \%$ & 206 & $60.6 \%$ & $9.5 \pm 3.0$ \\
\hline Precaution to prevent the & 2 & $.6 \%$ & 39 & $11.5 \%$ & 299 & $87.9 \%$ & $14.1 \pm 2.1$ \\
\hline transmission of the disease & & & & & & & \\
\hline Total & 2 & $.6 \%$ & 175 & $51.5 \%$ & 163 & $47.9 \%$ & $57.6 \pm 13.2$ \\
\hline
\end{tabular}


Table (5): Multivariate analysis logistic regression for factors affecting self care practices

\begin{tabular}{|c|c|c|c|c|}
\hline \multirow{2}{*}{ Factors affecting self-care practices } & \multirow{2}{*}{ Sig. } & \multirow{2}{*}{ OR } & \multicolumn{2}{|c|}{$95 \% \mathrm{CI}$} \\
\hline & & & $\mathbf{L L}$ & $\mathbf{U L}$ \\
\hline Education level & $<0.001^{*}$ & 0.394 & 0.313 & 0.495 \\
\hline Age & $0.003^{*}$ & 2.344 & 1.347 & 4.080 \\
\hline Income & $0.016^{*}$ & 0.307 & 0.118 & 0.800 \\
\hline Residence & $0.029^{*}$ & 0.381 & 0.160 & 0.906 \\
\hline Duration of disease (years) & 0.067 & 1.356 & 0.979 & 1.878 \\
\hline Clinical onset of disease & 0.137 & 0.421 & 0.135 & 1.317 \\
\hline Sex & 0.196 & 3.014 & 0.566 & 16.059 \\
\hline Marital status & 0.282 & 1.527 & 0.706 & 3.305 \\
\hline Work & 0.349 & 0.641 & 0.253 & 1.624 \\
\hline taking medications for associated diseases & 0.434 & 0.661 & 0.235 & 1.865 \\
\hline History of associated diseases & 0.870 & 0.928 & 0.379 & 2.273 \\
\hline
\end{tabular}




\section{References}

1. Nouroza F, Shaheena S, Mujtabab G and Noreenc S. An Overview on Hepatitis C Virus Genotypes and Its Control. Egyptian Journal of Medical Human Genetics 2015; 16(4): 291- 8.

2. Houghton M. "The long and Winding Road Leading to the Identification of The hepatitis C Virus". Journal of Hepatology 2014; 51(6):939-48.

3. EASL Recommendations on Treatment of Hepatitis C. European Association for the Study of the Liver. Journal of Hepatology 2015; (63) 199-236.

4. Georg D. Egypt has Highest Prevalence of Hepatitis C in the World: WHO, 2016.

5. Miller F, Abu-Raddad L. Evidence of Intense Ongoing Endemic Transmission of Hepatitis $\mathrm{C}$ virus in Egypt. Proceeding of National Academy of Sciences of the United States of America Journal.2010; 107 (33): 14757- 62.

6. Margolis H, Coleman P, Brown R. Prevention of Hepatitis B Virus Transmission by Immunization. An Economic Analysis of Current Recommendations. JAMA 1995; (274): 1201-8

7. Hogan M, Madayage T. Medical Surgical Nursing: Reviews\& Rationales, London: Pearson Prentice Hall Co.2004; 270.

8. Franciscus A. Sexual Transmission of Hepatitis C - HCV Advocate, February 2015.

9. Chen S, Morgan T. History of Hepatitis C Virus (HCV) Infection. International Journal of Medical Sciences 2016; 3(2):47-52.

10. El-Sayed O. Study of Some Factors Associated With Hepatic Steatosis in Chronic Hepatitis $\mathrm{C}$ and Its Impact on the Severity of Disease. Unpublished master thesis, Faculty of medicine, University of Alexandria, 2004; 1,3,31.

11. WHO: Guidelines For The screening, Care And Treatment Of Person With Chronic Hepatitis C Infection, 2016. Available at: http://apps.who.int/iris/bitstream/10665/205 $\underline{035 / 1 / 9789241549615 \text { eng.pdf. }}$
12. Waked I, Doss W, El-Sayed M. The Current and Future Disease Burden of Chronic Hepatitis C Virus Infection in Egypt. Arab J Gastroenterology 2014; 15(2):45-52.

13. Razavi H, Waked I, Sarrazin C. The Present and Future Disease Burden of Hepatitis C Virus with Today's Treatment Paradigm. J Viral Hepat 2014; 21(Suppl 1): 34-59.

14. Eldred K."Coping with Chronic Illness: Do Strategies Differ by Illness Type?" (2011). UNF Theses and Dissertations. 125.

15. Centers for Disease Control and Prevention. Chronic Disease Prevention and Health Promotion, 2010. Retrieved from http://www.cdc.gov/chronicdisease.

16. Tartakovsky M. What Self-Care Looks Like. Psych Central. Retrieved on November 4, 2017.

17. Dehkordi H, Mohammadi N, Nasrabadi A. Re-designing Orem's Self-care Theory for Patients with Chronic Hepatitis. Indian J Palliat Care 2016; 22(4): 395-401.

18. Olson M , Jacobson I. Role of The nurse Practitioner in the Management of Patients with Chronic Hepatitis C. Journal of the American Academy of Nurse Practitioners 2011,8(23): 35-40.

19. Franciscus A, Highleyman L. A guide to Understanding Hepatitis C. Hepatitis Journal Review: A Bi-Monthly Publication of the Hepatitis Support Project 2011; 4: 4, 5, 11-2.

20. Holtzman D. Traveler's Health. Atlanta: Center for Disease Control and Prevention; 2013.Chapter 3, Infectious Disease Related To Travel; 78.

21. Management of Hepatitis C A national Clinical Guidelines. Information about hepatitis C for patients and careers. 2006. Available at: http://www.sign.ac.uk/pdf/sign 92.pdf.

22. Bugge C. Enhancing Self Care and SelfManagement.2011- 2012. Available at: http://www.stir.ac.uk/.../research/.../enhanci ng self care andself

23. Ryan A, Wilson S, Taylo A, Greenfield S. Factors Associated With self-care Activities 
Among Adults in The United Kingdom . BMC Family Practice 2009, April, 5; 14131.

24. Kotz S, Balakrishnan N, Read CB, Vidakovic B. Encyclopedia of statistical sciences. 2nd ed. Hoboken, N.J.: WileyInterscience; 2006.

25. Kirkpatrick LA, Feeney BC. A simple guide to IBM SPSS statistics for version 20.0. Student ed. Belmont, Calif.: Wadsworth, Cengage Learning; 2013.

26. Evan, JD. (1996). Straight Forwards Statistics for The behavioral Science. Pacific Grove, CA: Brooks/Cole Publishing.

27. Branndt L. Gastroenterology and Bile Duct Disease. $9^{\text {th }}$ ed. New York: Elsevier Co. 2010; 1314, 19.

28. Danilova D, Gorrea M, Chammas M, Zambrini $\mathrm{H}$ and Marui S: Thyroid Hormone Disturbances Related To Treatment Of Hepatitis C With Interferon -Alpha And Ribavirin. Medical Clinic Journal 2011; 66 (15):1756-60.

29. Ibrahim $\mathrm{E}$ and Madian A: Impact of Hepatitis C on Health-Related Quality of Life in Egypt, Faculty of Nursing, Damanhour University. Journal of American Science 2011; 7(11).

30. Youssef N, Elkassas M, Farag A and Shepherd A: Health Related Quality of Live in Patients with Chronic Hepatitis C Receiving Sofosbuvir-Based Treatment, with and Without Interferon: A prospective Observational Study in Egypt. 21 January 2017

31. Mohamed Y, Mumtaz G, Riome S, Miller D and Abu-Raddad Li. (2013). The epidemiology of Hepatitis C virus in Egypt: A systemic Review and Data Synthesis. BMC Infect Dis 13: 288.

32. Abo-Elmataty P: Variability of Hepatitis C Virus. Hepatology 2014; 28(2): 5780-5783.

33. Porter L. Women and HCV. Hepatitis Journal Review: A Bio-Monthly Publication of the Hepatitis Support Project 2011; 1.2.2.
34. Alavi S and Hajiani E :Hepatitis C Infection :a reviews on Epidemiology and Management of Occupational Exposure in Health Care Workers For General Physicians Working in Iranian Health Net Work Setting. jundishapur Journal of Microbiology 2011;4(1):1.

35. Deakin T. Women and Hepatitis C: A resource for Women with Hepatitis C. Australia: Hepatitis Australia publication 2007; 2-72.

36. Benova I, Awad S. Miller F, Abbu-Raddad Li: Estimation OF Hepatitis C Virus Infections from Vertical Transmission in Egypt. Hepatology 2015; 61(3):834-42.

37. Jayasekera CR, Barry M, Roberts LR and Nguyen MH: Treating Hepatitis C In LowerIncome Countries N ENgl J Med 2014; 370:1869-71.

38. Suthar A and Harries A. Public Health Approach To Hepatitis C control in Low and Middle Income Counters. Journal List 2015; 12(3); > PMC4355406.

39. Amer F, Gohar $M$ and Youssef $M$ : Epidemiology of Hepatitis C Virus infection in Egypt International Journal of Tropical Disease \& Health 2015; 7(3):119-131,345 Article no 1JTDH.2015.065 issn: 22781005.

40. El-Berdan A:Assessment of Health Related Behaviors Among Patients With Viral Hepatitis. Un Published Master's Thesis, in nursing Science. Faculty of Nursing, Alexandria University 2014.

41. Mc Hutchision J, Goodman, Z, Patel K: Farglitizar Study Investigators. Farglitazar Lacks Antifibrotic Activity in Patients with Chronic Hepatitis C Infection. Gastroenterology 2010; 138(4):1365-73, 1373.el-2.

42. Jean B, Cortan R. A guide to understanding hepatitis C .A systemic. Review Journal Etiology 2010; 4 (3): 491- 500.

43. Proeschold-Bell R, Hoeppner B, Taylor B. An interrupted Time Series Evaluation of A hepatitis C Intervention for Persons with HIV. AIDS and Behavior Journal 2011; 5(8): 1721-8. 
44. Seaward BL. Principle and Strategies for Health Well being $2^{\text {nd }}$ ed. Boston: Jones and Bartlett 2009. Publisher; P.60.

45. Stoller E, Webster N, Blixen C. Management of Chronic Disease: A qualitative Study of Living with Hepatitis C Infection. American Journal of Health Behavior 2009; 33(4): 376- 90.

46. Highleyman L. HCV and Sleep Problems. Hepatitis Journal Review: A Bi-Monthly Publication of the Hepatitis Support Project 2010; 7(1):1-3.

47. Kallman S, Kleiner DE, Ghany G. and Park Y. 10-years Follow up After Interferon -a therapy for Chronic Hepatitis C. Journal of Hepatology 2010, 28(4): P.p.1121-25.

48. Sabry A. Study of Hepatitis C Virus Related Glomeruopathy. Egypt: Unpublished Doctorate Thesis, Faculty of Medicine, Mansoura University 2009; P.p.3-32.

49. Sallam SM. An epidemiological Study on Hepatitis In Alexandria. Egypt: Unpublished Doctorate Thesis. High Institute of Public Health, Alexandria University 2009; P.p.141-6.

50. Zuberi M. Hepatitis C:Education and Counseling Issue. J Addict Dis 2010; 20(1): 33-42.
51. Rashed HM, Thorlund K, Hauser G, Stimac $\mathrm{D}$, Mabrouk $\mathrm{M}$ et al. Peginterferon alpha-2a Is Associated with Higher Sustained Virology Response than Peginterferon Alfa$2 \mathrm{~b}$ in Chronic Hepatitis C : Systemic Review of randomization trials. Hepatology 2009,51(4): 1176-84

52. Khuwaja AR. Qureshi R, Fatmi Z. Knowledge About Hepatitis B and C Among Patients Attending Family Medicine Clinics In Karachi. Eastern Mediterranean Health Journal 2002; 8(6): 5-7.

53. Younossi Z, Nader Fm. And Bai C. A phase 11Dose Finding Study of Darbepoetin Alpha and Filgrastim for The management of Anemia and Neutropenia in Chronic Hepatitis Treatment. J Viral Hepat 2008; 20(1): 33-42.

54. Tamayo A, Shah S, Bhatia S. Correlates of Disease-Specific Knowledge Among Patients with Chronic Hepatitis B or Hepatitis C Infection in India. Hepatol Int 2016; 10(6): 988-95.

55. Garieb HA.QOL and Associated Factors in Patients with C Viral Liver Disease. Unpublished Master's Thesis, In Nursing Science. Faculty of Nursing, Ain Shams University, Egypt. 